\title{
EXPERIÊNCIAS E APONTAMENTOS DE PROFESSORAS DE CRECHE SOBRE INCLUSÃO ESCOLAR
}

\author{
EXPERIENCIAS Y APUNTES DE MAESTROS DE EDUCACIÓN INFANTIL ACERCA \\ DE LA INCLUSIÓN ESCOLAR
}

\section{EXPERIENCES AND NOTES FROM DAYCARE TEACHERS ABOUT EDUCATIONAL INCLUSION}

\author{
Carla Cilene Baptista da SILVA ${ }^{1}$ \\ Andrea Perosa Saigh JURDI ${ }^{2}$
}

RESUMO: O objetivo desse artigo é analisar e discutir os dados produzidos por professoras em relação às suas experiências em educação inclusiva com crianças de zero a três anos. Trata-se de um estudo qualitativo, do qual participaram 46 professoras de creches públicas de uma cidade de médio porte do litoral paulista, que responderam um questionário semiaberto, relatando suas experiências e dificuldades com relação à inclusão escolar nessa faixa etária. Os resultados apresentados, com base na análise de conteúdo temático, discutem as dificuldades quanto às experiências com inclusão escolar e as experiências bem sucedidas descritas pelas participantes. Acredita-se que este estudo pode contribuir para a discussão sobre a educação para todos na creche e para fomentar reflexões e novos estudos na área.

PALAVRAS-CHAVE: Educação Inclusiva. Creches. Professores.

RESUMEN: El objetivo de este artículo es discutir los datos producidos por las maestras con relación a sus experiencias en educación inclusiva con niños de cero a tres años. Tratase de un estudio cualitativo de lo cual han participado 46 maestras de guarderías públicas de una ciudad del litoral de San Pablo que han respondido a una encuesta medio abierta, por medio de cual han relatado sus experiencias y dificultades en relación a la inclusión escolar en esta franja etaria. Los resultados presentados con base en el análisis del contenido temático hablan de las dificultades en las experiencias con inclusión escolar y de las experiencias exitosas descritas por las participantes. Créese que este estudio puede contribuir para la discusión acerca de la educación para todos en las guarderías y que puede promover reflexiones para los campos afines.

\footnotetext{
${ }^{1}$ Universidade Federal de São Paulo (UNIFESP), Santos - SP - Brasil. Professora do Departamento Saúde, Educação e Sociedade e do Curso de Terapia Ocupacional Docente do Programa de Pós-Graduação Interdisciplinar em Ciências da Saúde e do Programa de Mestrado Ensino em Ciências da Saúde - modalidade profissional. Pós-doutorado em Educação pela Universidade de Aveiro, Portugal. ORCID: <https://orcid.org/0000-0001-9250-6065>. E-mail: carlaci@gmail.com

${ }^{2}$ Universidade Federal de São Paulo (UNIFESP), Santos - SP - Brasil. Professora do Departamento Saúde, Educação e Sociedade e do Curso de Terapia Ocupacional. Docente do Programa de Pós-graduação Interdisciplinar em Ciências da Saúde e do Programa de Mestrado Ensino em Ciências da Saúde - modalidade profissional. Doutora em Psicologia Escolar e Desenvolvimento Humano pelo Instituto de Psicologia da USP. ORCID: <http://orcid.org/0000-0002-1111-5562>.E-mail: andreajurdi@gmail.com
} 
PALABRAS CLAVE: Educación inclusiva. Guarderías. Maestros.

ABSTRACT: The goal of this paper is to analyze and discuss the data produced by the researchers regarding their experiences in inclusive education with children from ages zero to three. It is a qualitative study, of which 46 daycare teachers participated, all from public daycares of a city at the coast of São Paulo. They answered a semi-open questionnaire, where they reported their experiences and difficulties regarding educational inclusion of that age group. The results, presented based on analyzes of thematic content, discuss the hardships regarding experiences with school inclusion and the successful experiences as told by the participants. Our belief is that this study may contribute for the discussion about accessible daycare education, and that it may promote discussions in related areas.

KEYWORDS: Inclusive Education. Daycare. Teachers.

\section{Introdução}

No Brasil, a conquista da educação como direito social é firmada na Constituição Federal de 1988, assim como o direito das crianças com deficiência de frequentar a rede de ensino regular pública. A partir daí, com a promulgação da Lei de Diretrizes e Bases da Educação Nacional (Lei no. 9.304/96) - LDB (BRASIL, 2010a), tanto a educação de pessoas com deficiência quanto a Educação Infantil a partir da creche vêm sendo reorganizadas, discutidas e aprimoradas.

Posteriormente, as Diretrizes Curriculares Nacionais para a Educação Infantil (BRASIL, 2010b) e as Diretrizes Curriculares Nacionais Gerais para a Educação Básica (BRASIL, 2013) orientam sobre a organização do Projeto Político Pedagógico das instituições de Educação Infantil e estabelecem os grandes eixos norteadores da prática pedagógica que compõem a proposta curricular da Educação Infantil, que são: as interações e as brincadeiras.

No que diz respeito às políticas de Educação Especial, e acompanhando as mudanças ocorridas a partir da LDB, as Diretrizes Nacionais para a Educação Especial na Educação Básica (BRASIL, 2001) determinam que os sistemas de ensino - da creche ao ensino superior - devem matricular todos os alunos, cabendo às escolas se organizarem para o atendimento aos educandos com necessidades educacionais especiais. A atual Política Nacional de Educação Especial na Perspectiva da Educação Inclusiva (BRASIL, 2008) tem por um de seus principais objetivos assegurar a inclusão escolar de alunos com deficiência, transtornos globais do desenvolvimento e altas habilidades/superdotação. 
Numa análise crítica dos documentos oficiais sobre a garantia de atendimento ao público-alvo da educação especial nas creches, Vitta, Silva e Zaniollo (2016) apontam que há várias lacunas nas normativas quanto ao atendimento da criança com deficiência, transtornos globais do desenvolvimento e altas habilidades/superdotação para essa faixa etária. Apesar do aumento de pesquisas na área da Educação Infantil e Educação Especial, estudos específicos voltados para as creches ainda são incipientes.

As creches exercem papel fundamental no desenvolvimento infantil: são referências para a interação e exploração dos espaços, dos materiais, e possibilidades para adquirirem autonomia em ambientes adequados, seguros e estimulantes. Ao oferecer o cuidado e a educação para crianças até três anos de idade, as creches se responsabilizam também pela constituição psíquica dessas crianças. Desse modo, ao abordar o desenvolvimento infantil, é preciso pensar não apenas no indivíduo, mas na díade indivíduo-ambiente.

A educação como garantia de direito nessa faixa etária precisa trabalhar o binômio educar e cuidar de forma indissociada, ressignificando os contextos históricos, uma vez que a pré-escola sempre foi vista como o lugar que ensina e a creche vista como o local que cuida. Nesse sentido, cuidar e educar deve fazer parte da prática pedagógica desenvolvida na creche (VITTA; EMMEL, 2004; SOUZA; GARCIA, 2015).

Com o paradigma da inclusão escolar chegam às escolas crianças com as mais diferentes necessidades e singularidades que, por vezes, se distanciam do aluno idealizado pela educação, exigindo dos profissionais uma prática mais flexível e inclusiva. No momento atual, é importante que o professor possa compreender sua importância como ator no desenvolvimento dessas crianças, na importância da Educação Infantil como promoção do desenvolvimento, na creche como espaço de proteção, cuidado e educação das crianças de zero a três anos.

Com base em tais premissas, o objetivo desse artigo é analisar e discutir os dados produzidos pelos professores em relação às suas experiências em educação inclusiva com crianças de zero a três anos.

\section{Método}

Consiste em um estudo qualitativo de cunho exploratório e descritivo, cujos dados foram produzidos durante o curso de curta duração intitulado Formação de Educadores de 0 a 3 anos na perspectiva da educação inclusiva. O curso teve por objetivo geral proporcionar 
um espaço de formação continuada para professores de creche de um município de médio porte do litoral paulista, de acordo com as políticas públicas e na perspectiva da educação inclusiva.

Durante anos de 2014 e 2015 esse curso foi realizado por três semestres consecutivos, totalizando 100 participantes concluintes. Para cada turma foram realizados quatro encontros presenciais com duração de quatro horas cada. As temáticas abordadas foram definidas entre as docentes responsáveis e a equipe gestora da Secretaria Municipal de Educação, que garantiu e organizou a participação de pelo menos uma educadora de cada unidade escolar do município. Cabe ressaltar que todos os encontros ocorreram durante o horário de trabalho das participantes.

Do total de 100 professoras que concluíram o curso, 46 responderam o questionário semiaberto sobre suas experiências e dificuldades quanto à inclusão escolar. O questionário foi composto por dados gerais sobre a escola que trabalhava, sobre sua formação e tempo de experiência, e dados específicos sobre suas experiências com inclusão escolar.

As respostas dadas pelas participantes, além de comporem a amostra do presente artigo, foram material de discussão em pequenos grupos ao longo da formação, que visou, a partir da prática das participantes e de suas vivências, fornecer subsídios teóricos para a reflexão e ressignificação de conceitos e atitudes.

Todos os questionários foram organizados para análise das informações e os dados gerais foram tabulados de modo que permitiram caracterizar as participantes. As respostas dissertativas sobre suas experiências foram tratadas a partir do método de análise de conteúdo temático, proposto por Minayo (2012). Todas as participantes receberam códigos (P1; P2; P3 e assim sucessivamente) para identificar suas falas sem infringir a ética do sigilo de suas identidades.

Esse método de análise organiza-se em três polos cronológicos: pré-análise, exploração do material e tratamento dos resultados, interferência e interpretação. Para análise dos dados disponibilizados pelas professoras foi feita uma pré-análise, por meio de leitura e releitura, com o intuito de organizar o material disponível e formular hipóteses.

Após a conclusão dessa primeira etapa, ocorreu a exploração do material, que consiste essencialmente em operações de codificação feitas através da distribuição de trechos e fragmentos, de suas correlações, da identificação de núcleos de sentidos, da análise e agrupamento por temas, e então, a elaboração de uma redação final, organizando as ideias e 
fazendo articulações teóricas. Na última etapa houve a síntese interpretativa, articulando os objetivos do estudo, a base teórica adotada e os dados empíricos (MINAYO, 2012).

\section{Resultados e Discussão}

Todas as participantes eram mulheres. O tempo de trabalho na área da Educação variou entre menos de um ano e 30 anos, sendo em média 14 anos. Sobre o tempo específico de trabalho na creche, a média foi de 10 anos, sendo que a maioria possuía mais de 11 anos de experiência com essa faixa etária, como demonstrado na Tabela 1.

Tabela 1 - Tempo de Trabalho das Professoras em Creche

\begin{tabular}{lcc}
\hline $\begin{array}{c}\text { Tempo de Trabalho em } \\
\text { Creche }\end{array}$ & Número de Professoras & Porcentagem \\
\hline Menos de 2 anos & 4 & $8,6 \%$ \\
2 a 5 anos & 3 & $6,5 \%$ \\
6 a 10 anos & 12 & $26,1 \%$ \\
11 a 15 anos & 8 & $17,6 \%$ \\
16 a 20 anos & 10 & $21,7 \%$ \\
Mais de 21 anos & 9 & $19,5 \%$ \\
\hline TOTAL & 46 & $100 \%$ \\
\hline
\end{tabular}

Fonte: Autoria própria

Sobre a formação das professoras, todas possuíam nível superior, sendo $92 \%$ graduadas em pedagogia; as demais formações variaram entre letras, licenciatura em ciências e psicologia, e 22,5\% mencionou possuir o curso de Magistério, antigo curso para formação de professores de Educação Infantil e primeiros anos de alfabetização.

Cabe destacar que $46 \%$ delas possuíam algum curso de pós-graduação lato sensu, sendo que os mais mencionados foram Psicopedagogia, seguido de Gestão Escolar. Apenas duas participantes indicaram ter pós-graduação em Educação Especial e uma em Educação Inclusiva.

Os resultados encontrados nas questões específicas dizem muito das experiências das professoras de creche com relação à inclusão escolar. A seguir serão apresentadas e discutidas as respostas dadas pelas professoras, de acordo com as seguintes categorias temáticas: Dificuldades quanto às experiências com inclusão escolar e Experiências bem sucedidas.

\section{Dificuldades quanto às Experiências com Inclusão Escolar}


Algumas professoras relataram pouca experiência com inclusão escolar, demonstrando que as propostas de educação inclusiva ainda são pouco conhecidas pelos profissionais de creche, mesmo trabalhando há 7 e 13 anos respectivamente, como é o caso dos exemplos abaixo.

Apenas no ano de 2008 tive uma aluna com Síndrome de Down (P10).

Na verdade, em meus 13 anos de exercício da minha profissão, me deparei com poucas experiências com a inclusão escolar (P4).

O fato de algumas professoras relatarem pouca experiência com a inclusão escolar nas creches pode estar relacionado ao baixo número de matrículas de crianças com deficiência nessas unidades de ensino ou, ainda, pelo conceito que as professoras têm sobre educação inclusiva, localizando no aluno com deficiência a população específica da educação inclusiva.

Pacheco (2012) ressalta que a educação inclusiva é um produto histórico de uma época e de realidades educacionais contemporâneas que concebem a educação para todos e uma escola que acolha as diferenças e ofereça oportunidades de ser e aprender, não apenas para as crianças com deficiência. Para o autor, um projeto de inclusão é um ato coletivo e só tem sentido quando ultrapassa os muros da escola e proponha uma profunda transformação sociocultural.

A maioria das educadoras associam suas experiências com educação inclusiva à Educação Infantil, e não especificamente na creche.

Já tive algumas experiências diretas com inclusão na Educação Infantil, com crianças com paralisia cerebral, autismo e outros casos (P9).

Na Educação Infantil apenas tive contato com crianças autistas. (P7).

Em relação à associação direta entre aluno com deficiência e inclusão escolar, Ainscow (2009) ressalta que, em alguns países, o termo inclusão ainda é considerado como uma abordagem para atender crianças com deficiência dentro do contexto de sistemas regulares de educação. Porém, em âmbito internacional, o conceito de educação inclusiva tem sido compreendido de forma mais ampla, como uma reforma que apoia e acolhe as diversidades entre todos os sujeitos do processo educativo.

Uma participante que atua há 12 anos em creche mencionou ter tido várias experiências com essa faixa etária e enfatizou que pela idade não há um diagnóstico concluído. 
Durante todos esses anos na área da educação tive vários alunos que apresentaram dificuldades e necessidades especiais, porém, a maioria sem laudo ou diagnóstico fechado, o que era natural devido à faixa etária dos mesmos (P6).

Para algumas educadoras, a importância de ter um diagnóstico fechado, apesar da idade das crianças na creche, se justifica pelo apoio recebido pelos órgãos gestores, visto que muitos recursos só são disponibilizados para as unidades de educação mediante a comprovação de um laudo médico, como exemplifica a fala a seguir:

O único problema em relação a isso é que no momento só se tem um mínimo de apoio e estrutura tanto para os professores quanto para as crianças quando nos é apresentado um laudo (P6).

A questão do diagnóstico gera controvérsias. Se por um lado os professores o consideram importante para buscar respostas às características da criança e delinear estratégias pedagógicas de atuação, por outro lado, podem interferir negativamente para o prognóstico e para as ações junto à criança, gerando atitudes excludentes. Nesse sentido, Rossetti-Ferreira et. al. (2009) alertam que os resultados de avaliações e diagnósticos “[...] dão à família ou à escola/creche elementos que, muitas vezes, auxiliam a constituir a criança como competente ou deficiente, favorecendo sérios processos de exclusão" (p. 442).

Nos relatos dos professores sobre as dificuldades, ainda se faz presente o discurso em que o foco da inclusão está na criança, no seu comportamento e sua aprendizagem, e não em todo o contexto sociocultural e escolar que envolve o desenvolvimento infantil e as ações pedagógicas inclusivas.

As dificuldades existentes são: relacionamento dentro do grupo classe (agressividade), falta de atenção para determinadas atividades dirigidas, cumprir combinados, isolamento (P3).

Minha preocupação fica voltada para a agressividade e para as dificuldades com relação ao aprendizado $(P 1)$.

Ao mesmo tempo em que citam as questões de comportamento e aprendizagem como obstáculos do processo de inclusão escolar, as educadoras trazem também a dificuldade em lidar com as manifestações das crianças, em entendê-las e ter recursos para lidar com as mesmas.

No entanto, para Ainscow (2009), é importante que os educadores não tragam para a sala de aula as práticas especiais de educação, evitando a segregação, a exclusão e o preconceito em relação a esses alunos. $\mathrm{O}$ autor ressalta a necessidade de não focar apenas nas 
manifestações dos alunos, mas pensar de que forma a organização escolar, as atividades, as estratégias de ensino-aprendizagem têm sido modificadas para atender às necessidades desses alunos.

Enfatiza ainda que a falta de mudança organizacional provou ser uma das maiores barreiras para a implementação de políticas de educação inclusiva e propõe substituir a expressão necessidades educacionais especiais pela expressão obstáculos escolares ao aprendizado, cujo conhecimento levaria às modificações necessárias no cotidiano escolar (AINSCOW, 2009).

Para os profissionais da creche, um olhar ampliado para o desenvolvimento infantil e sobre como o ambiente e as relações podem propiciar outras experiências para as crianças, é parte importante de uma formação continuada.

As dificuldades mais apontadas pelas professoras estão relacionadas à falta de apoio de outros profissionais da equipe pedagógica, de recursos humanos, como professores auxiliares e mediadores, assim como de infraestrutura e materiais específicos, como apresentado no trecho a seguir:

No cotidiano do trabalho, a principal dificuldade é a falta de pessoal para auxiliar na sala e o despreparo de professores, equipe e todos os demais funcionários da escola para lidar com todos os tipos de inclusão escolar (P10).

Quanto às dificuldades apontadas sobre falta de recursos humanos, falta de condições estruturais e acessibilidade, as falas das participantes corroboram com alguns estudos (IDE; YAMAMOTO; SILVA, 2011; PEREIRA; MATSUKURA, 2013) sobre as queixas de professores relacionadas às ações para a educação inclusiva de crianças com deficiência, transtornos globais e altas habilidades na Educação Infantil, e em específico em creches.

Sobre o mediador, como denominado na rede municipal nos últimos anos, que corresponde aquele professor auxiliar que fica junto da criança com diagnóstico na sala de aula, há controvérsias. Se, por um lado, mediante diagnóstico concluído a escola tem direito a um mediador, por outro lado algumas professoras relatam como a presença deste pode prejudicar um processo efetivo de inclusão escolar.

Normalmente, quando existe um professor auxiliar, o aluno passa a ser dele e não daquele professor, daquela sala, escola. As pessoas deliberam que é seu aluno, e total responsabilidade sua, e não de todos (P 15). 
Algumas participantes chamaram a atenção para falta de ações Intersetoriais com profissionais da saúde, o que pode parecer prejudicar as ações no sentido de traçar estratégias conjuntas com todos os atores envolvidos no cotidiano da criança.

[...] há dificu/dades relacionadas à falta de informação a respeito de algumas síndromes; a questão da acessibilidade nas nossas escolas; a aceitação de alguns professores e principalmente, o apoio dos profissionais especialistas na troca de experiências e informações [... ] (P 38).

Os professores não têm contato com os profissionais da saúde e falta esclarecimentos da equipe técnica (P 18).

\section{Experiências Bem Sucedidas}

Apesar das dificuldades, há relatos de avanços, mesmo que estes digam respeito mais ao interesse e desempenho da equipe da escola do que das políticas efetivas ou mudanças de conceitos e atitudes socioculturais.

Continuamos vivendo a mesma problemática: salas numerosas, falta de profissionais para atendimento, falta de informação e comunicação com demais profissionais. Novamente, os avanços vêm ocorrendo devido ao interesse e boa vontade dos profissionais da unidade (P 26).

De acordo com alguns estudos (ANJOS; ANDRADE; PEREIRA, 2009; MATOS; MENDES 2015), é possível reconhecer o progresso da legislação brasileira e os esforços de professores e municípios em processos de construção de sistemas educacionais inclusivos. No entanto, há de se considerar a precariedade do sistema público brasileiro de educação, as inúmeras dificuldades relativas às concepções e atitudes frente às diferenças, bem como de promover ações educativas inclusivas.

Mesmo que com menor número e ênfase, as experiências bem sucedidas demonstram que algumas das unidades educacionais vêm desenvolvendo estratégias que tornam possíveis ações inclusivas para a primeira infância. Todos os relatos de experiências bem sucedidas apontam para ações coletivas, seja entre os profissionais da escola, entre estes e as famílias, ou ainda entre escola e profissionais especializados de serviços de saúde.

A escola em que atuo conta com a professora de Atendimento Educacional Especializado duas manhãs da semana. São realizadas reuniões entre a equipe gestora, a professora de AEE, o professor mediador e o de classe para discussão dos casos. Acredito que o acompanhamento com o aluno tem sido satisfatório (P 32). 
$\mathrm{Na}$ fala dessa participante, é importante ressaltar que a presença de uma professora de Atendimento Educacional Especializado se deve ao fato dessa creche funcionar conjuntamente com a pré-escola, pois esse professor especializado não se encontra nas unidades onde só atendem o público de zero a três anos.

Independente de ser um aluno público-alvo da educação especial, atuar em consonância e em parceria com a família é essencial para o desenvolvimento da criança.

Estamos juntas: equipe, mãe, professor titular e eu aprendendo a lidar com a criança (P 29).

Ainscow (2009) enfatiza a necessidade de a escola desenvolver melhor as relações com a família. Franco (2015) complementa que a criança e a família são um todo indissociável e que a família é a principal promotora do desenvolvimento, mais do que qualquer outro contexto profissional ou fator específico. Normalmente, afasta-se os pais das escolas, mas a educação é uma tarefa muito importante para ser executada somente pelos professores. Todos devem se responsabilizar, desempenhar suas funções e trabalhar juntos, atuando para a solução e não no reforço de falhas e problemas.

Os últimos dois relatos exemplificam a importância de se realizar um trabalho conjunto com diferentes áreas quando necessário. Apesar das normativas na perspectiva da Educação Inclusiva indicarem que se deve contar com ações Intersetoriais, assim como alguns estudos da área, na prática, poucas são as iniciativas nesse sentido, e poucos são os municípios que conseguem viabilizar essas estratégias.

Agendamos com a equipe multidisciplinar (do centro de reabilitação onde a criança era atendida) para que os professores pudessem assistir uma sessão de terapia ocupacional e juntamente com a Coordenadora Pedagógica e a Orientadora Educacional, conversar com os profissionais que atendem a criança. Isso trouxe mais segurança para a ação dos professores (P 40).

A criança chegou na escola usando goteiras e tinha muita dificuldade para andar [...] trabalhamos em parceria com a família, com os terapeutas da [...] e toda a equipe técnica, foi gratificante acompanhar o desenvolvimento do aluno em todos os sentidos (P 18).

\section{Considerações finais}


O artigo teve por objetivo discutir as ações relativas à inclusão escolar em creches a partir de experiências relatadas pelas professoras, o que permitiu apontar as dificuldades por elas encontradas e refletir sobre experiências bem sucedidas. Foi possível constatar que as professoras de creche ainda se referem a um segmento de alunos com deficiência como população alvo da educação inclusiva. Além disso, o sistema educacional enfatiza os laudos e diagnósticos para prover os alunos com dificuldade de apoio especializado na escola.

Reconhecer todas as crianças como sujeitos de direitos, reafirmando que sua proteção deverá ser integral, a qual é de responsabilidade da família, da sociedade e do Estado, implica em um atendimento a todas as crianças na Educação Infantil, em que o acolhimento e o cuidado devem ser preservados, que o educar, bem como o brincar, devem ser incorporados como garantia da qualidade na Educação Infantil e inclusiva.

Assim, pensar que o desenvolvimento e a educação da criança se dão, também, pelas relações e as formas como essas são estabelecidas, implica em pensar a visão e o papel dos profissionais envolvidos nesses processos.

No caso da inclusão escolar de crianças com deficiência e transtornos globais do desenvolvimento, se faz necessário propiciar estratégias de ação conjunta e intersetorial para que todas as dimensões envolvidas possam, de modo indissociável, contribuir para o desenvolvimento e bem-estar, assim como na construção de espaços e ações inclusivas.

Caberá também ao educador participar e se comprometer em tornar a creche inclusiva, não apenas para as crianças com deficiência, mas para todas as que a procuram.

Apesar dos resultados, o estudo realizado encontrou limitações em função do método utilizado e do número de participantes. Acredita-se que são necessárias outras pesquisas com métodos que visem abranger maior número de participantes, bem como que possibilitem aprofundar questões relativas ao tema.

\section{REFERÊNCIAS}

AINSCOW, M. Tornar a educação Inclusiva: como essa tarefa deve ser conceituada? In: FAVERO, O. et al. (Orgs.). Tornar a educação inclusiva. Brasília: UNESCO. ANPED, 2009. p. 11-23.

ANJOS, H. P.; ANDRADE, E. P.; PEREIRA, M. R. A inclusão escolar do ponto de vista dos professores: o processo de constituição de um discurso. Revista Brasileira de Educação, v. 14, n. 40, p. 116-129, jan./abr., 2009. 
BRASIL. Ministério da Educação. Secretaria de Educação Especial. Diretrizes Nacionais para a educação especial na educação básica. Brasília, DF: 2001.

BRASIL. Ministério da Educação. Política Nacional Educação Especial na Perspectiva da Educação Inclusiva. Brasília, DF: MEC, 2008.

BRASIL. Lei Darcy Ribeiro (1996). LDB: Lei de Diretrizes e Bases da Educação Nacional. 5.ed. Brasília, DF: Câmara dos Deputados, Coordenação Edições Câmara, 2010a.

BRASIL. Ministério da Educação. Secretaria da Educação Básica. Diretrizes curriculares nacionais para a educação infantil. Brasília, DF: MEC, SEB, $2010 \mathrm{~b}$.

BRASIL. Ministério da Educação. Secretaria de Educação Básica. Diretoria de Currículos e Educação Integral. Diretrizes Curriculares Nacionais Gerais da Educação Básica.

Brasília, DF: MEC, SEB, DICEI, 2013.

FRANCO, V. Introdução à Intervenção Precoce no desenvolvimento das crianças: com a família, na comunidade, em equipe. Évora: Edições Aloendro, 2015, 154 p.

IDE, M. G.; YAMAMOTO, B. T.; SILVA, C. C. B. Identificando possibilidades de atuação da terapia ocupacional na inclusão escolar. Cadernos de Terapia Ocupacional da UFSCar, v. 19, n. 3, p. 323-332, set./dez., 2011.

MARIOTTO, R. M. M. Cuidar, Educar e Prevenir: as funções da creche na subjetivação de bebês. São Paulo: Escuta, 2009, 160 p.

MATOS, S. N.; MENDES, E. G. Demandas de professores decorrentes da inclusão escolar. Revista Brasileira de Educação Especial, Marilia, v. 21, n. 1, p. 9-22, jan./mar., 2015.

MINAYO, M. C.; GOMES, S. F. D. (Org.). Pesquisa Social: teoria método e criatividade. Petrópolis, RJ: Vozes, 2012, 112 p.

PACHECO, J. Inclusão não rima com solidão. Editora: Wak, 2012, 104 p.

PEREIRA, P. C.; MATSUKURA, T. S. Inclusão Escolar e Educação Infantil: um estudo de caso. Revista Educação Especial, v. 26, n. 45, p. 125-144, jan./abr., 2013.

ROSSETTI-FERREIRA, M. C.; AMORIM, K. S.; OLIVEIRA, Z. M. R. Olhando a criança e seus outros: uma trajetória de pesquisa em educação infantil. Psicologia USP, São Paulo, v. 20, n. 3, p. 437-464, jul./set., 2009.

SOUZA, R. K.; GARCIA, E. S. Um novo olhar: a criança como sujeito de direito no campo da legislação e dos documentos que regem a educação. Perspec. Dial. Rev. Educ. Soc. v. 2, n. 3, p. 75-91, jan./jun., 2015.

VITTA, F. C. F.; EMMEL, M. L. A dualidade cuidado x educação no cotidiano do berçário. Paidéia, v. 14, n. 28, p. 177-189, set./dez., 2004. 
VITTA, F. C. F.; SILVA, C. C. B.; ZANIOLO, L. O. Educação da Criança de Zero a Três Anos e Educação Especial: uma Leitura Crítica dos Documentos que Norteiam a Educação Básica1. Revista Brasileira de Educação Especial, v. 22, n. 1, p. 9-26, jan./mar., 2016.

\section{Como referenciar este artigo}

SILVA, Carla Silene Baptista da.; JURDI, Andrea Perosa. Experiências e apontamentos de professoras de creche sobre inclusão escolar. Revista Ibero-Americana de Estudos em Educação, Araraquara, v. 14, n. esp. 1, p. 842-854, abr., 2019. E-ISSN: 1982-5587. DOI: 10.21723/riaee.v14iesp.1.12210

Submetido em:06/08/2016

Aprovado em: 21/09/2018 